\title{
AN EMPIRICAL STUDY ON REGIONAL WELFARE INEQUALITIES AND NATIONAL EXPENDITURE PRIORITIES
}

\author{
Jaewan Her*
}

\section{Introduction}

The allocation of public funds among regions has been one of the most important decisions made by the national governments of many countries. In particular, the question of whether such allocations actually contribute to the reduction of inter-regional welfare inequalities has been of great interest among regional scientists. To address this empirical question, however, we must answer the fundamental question of how to define a national government's perceptions of both the relative levels of regional welfare disparities and the relative effectiveness of various expenditures in reducing such inequalities. For example, how does the national government implicitly assign relative weights to economic factors such as income and employment in comparison to other socio-environmental factors such as public safety, education, housing and air pollution when making regional welfare comparisons? Similarly, how does the national government implicitly weigh the relative effectiveness of public works projects against revenue sharing programs in reducing perceived welfare disparities? ${ }^{1}$

To our knowledge, there have been no empirical attempts to measure such governmental tradeoffs, mainly due to the absence of an appropriate method. Recently, however, an interesting programming approach that can deal with this dual measurement problem has been proposed by Smith (1981). Although his approach is in essence an indirect one, it is very appealing, particularly from the empirical point of view since all computations can be easily done in a linear programming framework. In spite of the attractiveness of the Smith method, it has not yet been applied empirically.

This paper is a first attempt aimed at measuring such implicit governmental tradeoffs based on the Smith approach. A hypothesis relating regional welfare inequalities with the regional allocation pattern of government expenditures is established in the next

\footnotetext{
*Department of Regional Science, University of Pennsylvania. An early version of this paper was presented at the 1986 Southern Regional Science Association Meeting in New Orleans, Louisiana. Thanks are due to three anonymous referees of this journal for helpful comments and suggestions.
}

section. Also, the method suggested by Smith (1982) to test this hypothesis will be briefly introduced. The following sections will then describe the data used in this analysis, and present the empirical results and their implications. Finally some concluding remarks are made.

\section{The Hypothesis and Testing Method}

Let us assume a nation consisting of $\mathbf{R}$ political regions. We then define a set of regional indicators $\mathrm{s}^{\mathrm{i}}$ $(i=1, \ldots, N)$ reflecting the socio-economic and environmental characteristics of each region. It is further assumed that the national government perceives the welfare level of region $r$ by a set of such regional indicators

$$
\text { (1) } S_{r}=\left(s^{1} \ldots, \ldots, S^{1} \ldots, \ldots, N_{r}\right)(r=1, \ldots, R)
$$

where $s_{r}^{1}$ denotes a regional indicator $i$ in region $r$ such as income level, unemployment rate, indices of education and health, air pollution emission, or welfare facilities.

Although this set can describe the various welfare aspects of each region reasonally well, it is clear that tradeoffs arise among regional indicators when making interregional comparisons of welfare due to the multidimensional nature of such a set ${ }^{2}$. As an attempt to avoid such a problem, let us assume that the interregional welfare comparisons by the national government can be represented by means of a linear regional-welfare function:

$$
\text { (2) } \mathrm{W}(\mathrm{Sr})=\sum_{\mathrm{i}=1}^{\mathrm{N}} \alpha^{\mathrm{i}} \mathrm{s}_{\mathrm{r}}^{\mathrm{i}}=\alpha^{\prime} \mathrm{S}_{\mathrm{r}} \quad \mathrm{r}=1, \ldots, \mathrm{R}
$$

where the welfare weight vector $\alpha=\left\{\alpha^{1} \ldots, \alpha N\right\}$ consists of positive weights $\alpha^{1}$ which reflect the national government's implicit valuations of the relative welfare implications of each regional indicators $s^{1}$. In terms of this representation, we then assume that whenever $W\left(S_{r}\right) \geq W\left(S_{u}\right)$, the national government regards the overall welfare level in region $r$ to be at least as high as that in region $u$. Needless to say the implicit weights $\alpha$ are seldom made explicit, and can only be revealed indirectly in terms of observed governmental decision behavior. 
On the other hand, in responding to perceived regional welfare inequalities, it is assumed that the national government has a number of policy variables by which it can stimulate relative regional growth, and hence can control the relative levels of the regional indicators. For simplicity, assume that such policy variables can be characterized in terms of a set of government expenditure variables $\mathrm{g}_{\mathrm{j}}$. In addition, it is assumed that the regional policy of the national government toward each region 4 can be characterized by means of an expenditure set

$$
\text { (3) } \mathrm{Gr}=\left\{\mathrm{g}_{\mathrm{r}}^{1}, \ldots, \mathrm{g}_{\mathrm{r}}, \ldots, \mathrm{g}_{\mathrm{r}} \mathrm{M}_{\mathrm{r}}\right\} \quad \mathrm{r}=1, \ldots, \mathrm{R}
$$

where $g \mathrm{j}_{\mathrm{r}}$ denotes the level of government expenditure variable $\mathbf{j}$ in region $\mathbf{r}$ such as federally funded public works projects, urban or community development programs, and direct revenue transfers to regional governments. ${ }^{3}$

Under this definition of an expenditure set, it is clear that comparisons among possible expenditure sets for a given region will generally involve tradeoffs among the levels of one or more expenditure variables. Hence it is assumed, as in the case of regional welfare comparisons, that the government's comparisons of the relative effectiveness of each expenditure set $G_{r}$ can be represented by some implicit linear effective expenditure function:

$$
\text { (4) } E\left(G_{r}\right)=\sum_{i=1}^{N} \beta j g j_{r}=\beta^{\prime} G_{r} \quad r=1, \ldots, R
$$

where the positive expenditure weight vector $\beta=$ $\left\{\beta^{1}, \ldots, \beta^{M}\right\}$ reflects the national government's implicit evaluations of the relative effectiveness of each expenditure variable $j$ in improving regional welfare levels. The implicit weights $\mathrm{e}^{j}$ are also seldom made explicit, and can be revealed only in terms of observed governmental decision behavior.

If the national government does in fact seek to reduce perceived disparities in regional welfare levels, it is reasonable to hypothesize that higher effective expenditures $E\left(G_{r}\right)$ will be allocated to regions $r$ with lower welfare levels $W\left(S_{r}\right)$. Let us call this the hypothesis for regional allocation pattern of government expenditures (RAPGE). In terms of equations (2) and (4), this hypothesis can be stated that, given sets of regional indicators $\left\{S_{1}, \ldots, S_{R}\right\}$ and sets of expenditure variables $\left\{G^{1}, \ldots, G_{R}\right\}$, there exist positive vectors, $\alpha$ and $\beta$, such that for all pairs of regions $r$ and $u$

(5) $\alpha^{\prime} S_{r} \geq \alpha_{\ni} S_{u} \Longleftrightarrow \beta_{\ni} G_{u} \leq \beta^{\prime} G_{u}$
In this context, it is clear that testing RAPGE is logically equivalent to finding positive vectors $\alpha$ and $\beta$ satisfying (5) for the given data S and G.

Smith (1982) has proposed a programming method to compute such weights. To see his approach, let us define $\mathrm{R}^{\mathrm{N}}, \mathrm{R}^{\mathrm{N}}$, and $\mathrm{R}^{\mathrm{N}_{+}}$as $\mathrm{n}$-dimensional euclidian space, the non-negative orthant, and the positive orthant, respectively. Since (5) holds for a pair of regions $(r, u)$ if and only if it also holds for the pair $(u, r)$, it is enough to consider only those pairs of regions $(r, u)$ with $r<u$. Furthermore, since there are exactly $R(R-1) / 2$ such pairs, we relabel these pairs as $\left(\mathrm{r}_{\mathrm{i}}, \mathrm{u}_{\mathrm{i}}\right)$ with an index $\mathrm{i} \mathrm{E} \mathrm{I}=\{1, \ldots, \mathrm{R}(\mathrm{R}-1) / 2\}$. We also define the associated residual vectors $\mathrm{X}_{\mathrm{i}}$ and $\mathrm{Z}_{\mathrm{i}}$ for each $\mathrm{i}$ in $\mathrm{I}$ as $\mathrm{X}_{\mathrm{i}}=\mathrm{S}_{\mathrm{ui}}-\mathrm{S}_{\mathrm{ri}}$ and $\mathrm{Z}_{\mathrm{i}}=\mathrm{G}_{\mathrm{ri}}-\mathrm{G}_{\mathrm{ui}}$, respectively. Then (5) can be stated more compactly in terms of residual vectors

(6) $\quad \alpha^{\prime} X_{i} \geq 0 \Longleftrightarrow \beta^{\prime} Z_{i} \geq 0$ (i E I)

Smith then showed that if a solution set $\left(\mu^{*}, \alpha^{*}\right.$, $\beta^{*}$ ) satisfies the following two linear programs simultaneously, and furthermore $\mu^{*}$ is positive, then the resulting vectors $\alpha^{*}$ and $\beta^{*}$ always satisfy the relation $(6)^{4}$.

\section{Linear Program (A)}

(7) maximize: $\mu$ $(\mu, \beta)$

(8) subject to: $\mu-\left(\alpha^{\prime} X_{i}\right) Z_{i}^{\prime} \beta \leq O$ (i E I)

(9) $\beta E C_{M}=\left\{\left.\beta E R^{M}\right|^{M} \leq \sigma_{M} \beta<M+1\right\}$

where $\sigma^{M}=(1, \ldots, 1)$ is the unit vector in $R^{M}$ and the value of $\alpha$ is fixed.

Linear Program (B)

(10) mazimize: $\mu$ $(\mu, \alpha)$

(11) subject to: $\mu-\left(\beta^{\prime} Z_{i}\right) X_{i}^{\prime} \alpha \leq O$ (i E I)

(12) $\alpha E \mathrm{C}_{\mathrm{N}}=\left\{\alpha \mathrm{ERN}_{\mathrm{o}} \mathrm{N} \leq \alpha \leq \mathrm{N}+1\right\}$

where $\sigma{ }^{\prime} N=(1, \ldots, 1)$ is the unit vector in $\mathrm{R}^{\mathrm{N}}$ and the value of $\beta$ is fixed.

Furthermore Smith showed that these simultaneous programs can be effectively solved by an iterative procedure ${ }^{5}$. In addition, since such iterative 
computations are usually very costly, Smith proposed an approximation procedure which is simpler to solve and at least gives good starting values for such iterations.

Note that if we can find some $\alpha$ and $\beta$ such that $\alpha^{\prime}$ $X_{i}=\beta^{\prime} Z_{i}$ for all $i$ in $I$, then (6) would be automatically satisfied. Hence one approximation approach to satisfying (6) is to find $\alpha$ and $\beta$ such that the sum of squared differences between $\alpha^{\prime} x_{i}$ and $\beta^{\prime} Z_{i}$ are as small as possible. In other words, find $\alpha$ and $\beta$ satisfying the following minimization problem

$$
\underset{\mathrm{i} E \mathrm{I}}{\operatorname{mimize}} \quad \Sigma \quad\left(\alpha^{\prime} \mathrm{X}_{\mathrm{i}^{-}} \boldsymbol{\beta}^{\prime} \quad \mathrm{Z}_{\mathrm{i}}\right)^{2}
$$

Hence if we solve this problem subject to the two positivity constraints (9) and (12), then this becomes a standard quadratic program. This quadratic problem can be solved by a linear programming technique such as a simplex method. If the resulting $\alpha$ and $\beta$ by this square approximation procedure satisfy (6) for all $i$ in $I$, then the HRAPGE is verified. If not, these vectors can serve by construction, as good starting values for solving the above simultaneous linear programs.

More simply, if we ignore the positivity constraint for the present and impose some constraints such as (15) to avoid the inherent scale problem in (13), then the above minimization problem will be the following maximization problem:

$$
\begin{aligned}
& \begin{array}{lllll}
\operatorname{maximize}: & \boldsymbol{\alpha}^{\prime} & \mathrm{X} & Z^{\prime} & \boldsymbol{\beta}
\end{array} \\
& \text { subject to: } \quad \alpha^{\prime} X^{\prime} X^{\prime} \alpha=1=\beta^{\prime} Z Z^{\prime} \beta
\end{aligned}
$$

where $X=\left\{X_{i}^{\prime} \mid\right.$ i E I $\}$ and $Z=\left\{Z_{i}^{\prime} \mid\right.$ i $E$ I $\}$

Note that this is computationally equivalent to the wellknown canonical correlation problem. Consequently, the weight vectors satisfying this maximization problem can be obtained by the standard eigenvalue technique.

If the resulting $\alpha$ and $\beta$ by this least square approximation procedure satisfy (6) for all $\mathrm{i}$ in $\mathrm{I}$, and in addition are positive, then the HRAPGE is verified. If not, these vectors again can serve, by construction, as good starting values for solving the above simultaneous linear programs.

\section{The Data}

There appears to be no generally acceptable way of representing the data $S_{r}$ and $G_{r}$. We assume in this study that regional welfare can be represented as a function of six broadly defined regional factors: economics, education, environment, health, political and social factors. Then, instead of using surrogates to represent these factors ${ }^{6}$ as in conventional studies, we construct six corresponding aggregated indices known as quality of life $(Q O L)$ indices from 75 variables ranging from individual income and wealth, income distribution, political participation, pollution, educational attainment, and individual equality, to economic structure, government performance, environmental protection, transportation, and crime. Selection of the data and calculation of the associated indices mainly follow Smith (1973) and Liu (1976). The composition and the associated data sources for these six QOL indices are presented in Appendix 1.

In addition, since the computed results are likely to be sensitive to the method of constructing the QOL indices, another set of $8 \mathrm{QOL}$ indices ${ }^{7}$ is also constructed based on 20 variables to investigate such a sensitivity problem.

The data $G_{r b}$ are supposed to represent, by definition, the expenditure categories which can be regarded as regional polices aimed at stimulating regional growth. It is difficult, however, to decide what expenditure programs should be perceived as regional policy expenditures since it has been argued that the United States does not currently have a set of strong, explicit regional policies. Moreover some federal government studies show that not only were the impacts of most explicit regional policy programs insignificant, but they also accounted for only a small proportion of total federal expenditures (Richardson, 1978).

On the other hand, there is no doubt that many government expenditures aimed at achieving nonspatial objectives in fact discriminate in favor of some regions and against others. Hence some regional scientists such as Alonso have called such nonspatial expenditures implicit regional policies. Since such implicit policies usually occupy larger budgets and discriminate heavily among regions, their impacts are quantitavely more significant ${ }^{8}$.

To reflect all these implicit and explicit regional policy expenditures, we use the total flow of federal funds as the data for $G_{r}$. The flow of federal funds consists of eight categories: five expenditure categories (Direct Payments to Individuals, Procurement, Federal Aid to States, Salaries and Wages, and Other Expenditures) and three tax categories (Corporate Income Tax, Individual Income Tax, and Other Taxes).

All statistics are mainly collected for the 48 contiguous states 9 for the year 1982 based on various government periodicals. Then the 48 states are 
aggregated into nine census regions ${ }^{10}$ (New England, Mid Atlantic, East North Central, West North Central, South Atlantic, East South Central, West South Central, Mountain, and Pacific regions) to reduce the associated computational burdens. As a result, the suffix $i$ in the above equations runs from 1 to 36.

\section{Testing Results}

We first compute the weight vectors $\alpha$ and $\beta$ by the two least square approximation procedures, the quadratic programs and the eigenvalue techniques, for the six Quality of Life (QOL) indices. Table 1 presents the results. While all parameters from the quadratic program are positive, some estimates from the eigenvalue procedure are negative. Moreover, when we substitute all these computed weights into (6), the parameters from the quadratic program turn out to satisfy (6) for all $i$ while those from the eigenvalue technique result in three reversals. In the above least square appoximation framework, this implies that for the given data of six QOL indices and the flow of federal funds, the RAPGE hypothesis is verified by the quadratic programming procedure, but not by the eigenvalue procedure. The computed weights from the quadratic program then automatically reflect by definition the implicit governmental perceptions of the relative importance of each regional welfare variable in making regional welfare comparisons, and of the relative effectiveness of each expenditure program in reducing perceived welfare disparities among the regions.

The relative magnitude of welfare in the third column of Table 1 suggests that, in comparing regional welfare disparities among regions, the federal government attaches relatively higher weights to the social index (4.826) and the economic index (1.021), but relatively lower weights to the educational index (O.O.), health index (0.0) and political index ((0.046). Since the importance of economic factors in regional welfare has been well known, their high values are not surprising. The fact, however, that the social index has a considerably greater value than the economic index is an interesting result. Note that most of the existing studies on interregional disparities have paid attention to economic factors, especially to income, based on the conventional belief that these factors are the most important policy variables (for example, Biehl, 1980). Our result, however, does not support such an argument. It supports, rather, those who have argued that such a justification is too weak an excuse to neglect other aspects of regional welfare (Richardson,
1976, and Reiner, 1974).

On the other hand, the ranking among expenditure weights indicates that the expenditure category "Grant in Aid" is perceived as the most effective program in reducing regional welfare inequalities. This result is durable because it includes many distributive expenditure programs such as public works programs and community development programs. Also the higher effectiveness of the category "Individual Income Tax" is reasonable due to its progressive nature, whereas it is difficult to explain why the expenditure category, "Wages \& Salaries," is perceived to be more effective than the category "Procurement" or "Direct Payments to Individuals".

As explained before, other tests are done for the eight QOL indexes so as to investigate the sensitivity of the computed results to the type of data used. The results are presented in Table 2. Not surprisingly, the computed results in this case are quite different, and furthermore, the resulting weights by both approximation procedures fail to satisfy (6). For example, the computed weights by the quadratic program and by the eigenvalue technique have resulted in 9 reversals and 15 reversals when substituted into (6), respectively.

Since the approximation procedures have failed to verify the hypothesis for the case of eight $\mathrm{QOL}$ indices, the simultaneous linear programs (7) - (11) have been solved by the suggested iterative method with starting values based on the two approximation procedures as well as on a unitary value. Table 3 summarizes the results. First note that the iterative method results in a quick convergence. For example, a convergence occurred after 3 iterations when the starting values are provided by the quadratic program, and after 7 iterations when the initial values are given by the eigenvalue technique. This result suggests that the simultaneous program is also operationally durable. Note also that all objective values at converging points $\left(\mu^{*}\right)$ are positive. In our context, this implies that all three sets of weight vectors satisfy relation (6), and hence the RAPGE hypothesis for the given data.

Let us investigate the properties of the computed weights. The rankings of the computed welfare weights and the expenditure weights are quite different among the three sets. For example, the weight of the education index is ranked fourth in the third column, sixth in the fifth column and third in the last column. This conflicting result is essentially caused by the inherent non-uniqueness problem of the simultaneous program. Hence we must be cautious in interpreting the results. One way to avoid such a conflict is to consider only 
those properties which are common to all three weights in Table 3. By this way, we can observe two interesting properties here: i) both the public safety index and the air pollution index have greater values than the employment index or the income index, and ii) the weights of individual income and employment tax are higher than that of any other tax categories. In particular, note that the first property is consistent with previous results in Table 1 in the sense that there are other social or environmental factors which are perceived more importantly than economic factors in regional welfare comparisons. Hence this result also supports our previous assertion that noneconomic factors, in the study of regional inequalities, have been too often neglected without any sound empirical evidence.

\section{Concluding Remarks}

As an attempt to study the implicit governmental tradeoffs arising both in making regional welfare comparisons and in evaluating the effectiveness of various expenditure programs on reducing the perceived regional inequalities, a hypothesis describing the relation between regional welfare inequalities and the regional pattern of federal expenditures has been tested using the new methodological framework proposed by Smith. The important findings of our study can be summarized as follows.

First, the observed data strongly support the main hypothesis: the federal government allocates relatively more effective expenditures to regions with relatively lower welfare levels.

Second, in spite of the high weights attached, economic factors are perceived as relatively less important variables than certain noneconomic factors such as environmental quality in making interregional welfare comparisons.

Finally, it is difficult to find any consistent patterns in national expenditure priorities due to the sensitivity of the results to the type of data.

It must be born in mind, however, that this study still has several shortcomings associated with the data and the testing method. In particular,

i) the sensitivity of the results to the degree of spatial disaggregation has not been investigated;

ii) the interregional feedback effects of government expenditures are neglected for simplicity, which may be difficult to justify in a system as open as a region of a nation, and;

iii) since the requirement of strict ordering in Smith's method is in general unrealistic, it is desirable to extend it to a statistical method which can allow an ordering failure. In this respect, it is hoped that the results of this paper are interpreted as tentative rather than conclusive.

\section{FOOTNOTES}

${ }^{1}$ Most existing studies on the relationship between regional welfare inequalities and the regional allocation pattem of national expenditures have avoided these tradeoff problems both by representing regional welfare in terms of a single indicator such as income and by assuming that a unit of expenditure in each expenditure category is equally effective (see for example, Cameron, 1970. Catsambas, 1975, Pack, 1980, 1982, and Greytak et al. 1978).

${ }^{2}$ For example, in comparing the sets $S_{\mathrm{T}}=$

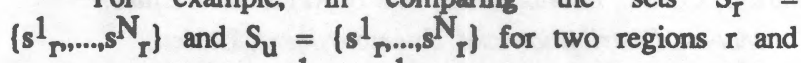
$u$, if the condition $s_{r}^{1} \geq s_{u}^{1}$ were to hold for all $i=$ $1, \ldots, N$ then it is reasonable to assume that the national government perceives the welfare level of region $\mathrm{r}$ to be at least as high as that in region u. However, if neither $S_{r} \geq S_{u}$ nor $S_{u} \geq S_{r}$ were true, then any overall comparison of regional welfare levels must necessarily involve implicit tradeoffs between the levels of two or more regional indicators.

${ }^{3}$ Federal revenues withdrawn from each region (such as through tax) can be regarded as negative expenditure variables.

${ }^{4}$ Refer to Smith (1982) for a more technical discussion.

5 The iterative procedure adopted in this study was i) with some candidate expenditure weight vector $\beta$ o, solve the Linear Program (B) and get $\left(\mu_{\mathrm{BO}}, \alpha_{0}\right)$, ii) by starting $\alpha_{0}$, solve the Linear Program (A) and find $\left(\mu_{\mathrm{Al}}, \beta_{1}\right)$, iii) if $\mu_{\mathrm{Al}}=\mu_{\mathrm{BO}}>0$, then finished, otherwise keep doing this process.

${ }^{6}$ For example, using income as a surrogate for the economic factors and air pollution emission for the environmental factors.

${ }^{7}$ These are 1) health index, 2) public safety index, 3) education index, 4) employment index, 5)income index, 6) housing index, 7) leisure and outdoor recreation index and 8) pollution index. The composition of these indices is given in Appendix 2.

${ }^{8} \mathbf{A}$ good example is defense expenditures. It is widely known that the defense spending in the United States has heavily favored the South and West. To some extent, the defense contracts were a stimulus to regional growth and hence partially accounted for the relatively high income growth rate of the South and West. 
${ }^{9}$ Hawaii, Alaska, and the District of Columbia are not included because of their special place in the federal budget.

10 There have been two different sets of macro regions used in regional data analysis in the United States. The first set is eight regional classifications developed by the Regional Economics Devision of the U.S. Department of Commerce. The second set is nine regions adopted by the Bureau of the Census. In this dissertation, the second set will be mainly used.

\section{REFERENCES}

Advisory Commission on Intergovernmental Relations, RegionaL Growth: Historic Perspective, by Janet Rothenberg Pack, Washington, D.C., U.S. Government Printing Office, June 1980.

Bartels, C.P.A., Economic Aspects of Regional Welfare, Income Distribution and Unemployment, Leiden: Martinus Nijhoff, 1977.

Bartels and P. Nijkamp, "An Empirical Welfare Approach to Regional Income Distribution", Socio-Economic Planning Sciences, 10 (1976), 117-128.

Biehl, D., "Determinants of Regional Disparities and the Role of Public Finances", Public Finance, vol. 35, No. 1, 1980.

Cameron, G. G., Regional Economic Development; The Federal Role, 1970, AMS Press, New York. Catsambas, T., Regional Impacts of Federal Fiscal Policy, Lexington Books, 1975.

Coates, B. E., Johnson, R. J., and Knox P. Geography and Inequality, Oxford,England: Oxford University Press, 1977.

Environmental Protection Agency, National Emission Report, 1984, Washington, D.C., U.S. Government Printing Office.

tan Areas: A Statistical Analysis, Praeger Publishers. 1976.

Pack, R. R., "The States' Scramble for Federal Funds: Who wins, Who loses?", Journal of Policy Analysis
Greytak, D. and Mchugh, R., "The effects of federal income taxation and inflation on regional in equalities", Journal of Regional Science, vol. 18, No. $1,1978$.

Liu, B. C., "Quality of Life: Concept, Measure and Results" The American Journal of Economics and Sociology, vol. 34, No. 1, 1975.

Liu, B. C., Quality of Life Indicators in U>S. Metropoliand Management, vol. 1, No. 2, 1982, pp. 175- 195.

Reiner, T. A., Welfare Differences Within a Nation, Procedings of Regional Science, 1974.

Richardson, H. W., "Efficiency and Equity", in H. Folmer and J. Oosterhaven (eds.), Spatial Inequalities and Regional Development, The Hague: Martinus Nijhoff, 1977.

Richardson, H. W., Regional Economics, University of Illinois Press, 1978.

Smith, D. M., The Geography of Social Well-Being in the US., New York: McGraw-Hill, 1973.

Smith. T. E., A Framework for the Joint Analysis of Expenditure Priorities, Working Paper No. 7 Working Papers in Regional Science a Transportation, Department of Regional Science, University of Pennsylvania, 1978.

Smith, T. E., "A Representational Framework for the Joint Analysis of Regional Welfare Inequalities and National Expenditure Priorities", JournalofRegional Science, vol. 21, No. 2, 1981, 187-202.

U.S. Bureau of the Census, Census of Population, 1980.

U.S. Department of Commerce, Bureau of the Census, Statistical Analysis of United States., 1984 and 1985 Washington, D.C.: U.S. Government Printing Office.

U.S. Department of Commerce, County and City Data Book, 1983, Washington, D.C.: U.S. Government Printing Office.

U.S. Department of Education, National Center for Education Statistics, Digest of Education Statistics, 1980-1981. 
TABLE 1

Results of Least Square Approximation Procedures

(6 Quality of Life Indexes )

Variable

Name

\section{Welfare Variable}

economic index

1.021

0.000

0.108

0.000

0.046

4.826

social index

Expenditure Variable

direct payments to individuals

0.000

0.048

procurements

0.000

4.832

1.822

0.000

0.000

1.304

0.000
Eigenvalue $^{b}$ grant in aid

salaries and wages

other expenditures

corporate income tax

individual income tax

other tax revenue

Coefficient Estimates

Quadratic ${ }^{a}$

0.324

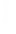




\section{TABLE 2}

Results of the Least Square Approximation Procedures

( 8 Quality Of Life Indexes)

Variable

Coefficient Estimates

Name

Quadratic $^{2}$

Eigenvalue $^{\mathrm{b}}$

\section{Welfare Variable}

health index

0.000

$-0.040$

public safety index

1.918

$-0.102$

education index

0.000

0.154

employment index

1.374

0.270

income index

0.000

0.318

housing index

0.000

0.248

leisure and recreation index

0.060

$-0.009$

air pollution index

4.648

$-0.166$

Expenditure Variable

direct payments to individuals

0.000

$-0.118$

procurements

0.000

0.043

grant in aid

2.788

$-0.425$

salaries and wages

1.867

0.075

other expenditures

0.000

$-0.098$

corporate income tax

1.216

0.089

individual income tax

2.129

$-0.479$

other tax revenue

0.000

0.006

\footnotetext{
a)Minimize: $\quad S_{i}\left(a^{\prime} X_{i}-b^{b} Z_{i}\right) 2$ subject to: i) $6 \leq S_{k} a^{k} \leq 7\left(a^{k} \geq 0\right)$, and ii) $8 \leq S_{j} \quad b^{j} \leq 9\left(b^{j} \geq 0\right)$.

$b^{\text {Maximize: }} \quad a^{\prime} X Z^{\prime} B \quad$ subject to: $a^{\prime} X X^{\prime} a=1=b^{\prime} Z Z^{\prime} b$
} 
TABLE 3

Results of the Bilinear Programming Procedure

( 8 Quality of Life Indexes )

\begin{tabular}{|c|c|c|c|}
\hline \multirow{3}{*}{$\begin{array}{l}\text { Variable } \\
\text { Name } \\
\text { Welfare Variable }\end{array}$} & \multicolumn{3}{|c|}{ Coefficient Estimates } \\
\hline & Quadratic $^{\mathrm{a}}$ & Eigenvalue $^{\mathrm{b}}$ & Unitary $^{c}$ \\
\hline & & & \\
\hline health index & 0.000 & 0.000 & 0.272 \\
\hline public safety index & 2.362 & 1.956 & 2.117 \\
\hline education index & 0.213 & 0.000 & 0.962 \\
\hline employment index & 0.333 & 1.680 & 0.616 \\
\hline income index & 0.900 & 0.390 & 0.000 \\
\hline housing index & 0.000 & 0.016 & 0.000 \\
\hline leisure and recreation index & 0.000 & 0.000 & 0.000 \\
\hline air pollution index & 5.192 & 4.958 & 5.033 \\
\hline Expenditure Variable & & & \\
\hline direct payments to individuals & 0.000 & 0.000 & 0.000 \\
\hline procurements & 0.000 & 1.155 & 0.153 \\
\hline grant in aid & 0.000 & 0.000 & 0.000 \\
\hline salaries and wages & 3.612 & 4.651 & 0.000 \\
\hline other expenditures & 0.000 & 0.755 & 0.000 \\
\hline corporate income tax & 0.119 & 0.000 & 1.627 \\
\hline individual income tax & 5.269 & 2.440 & 6.956 \\
\hline other tax revenue & 0.000 & 0.000 & 0.264 \\
\hline Number of iterations & 3 & 15 & 7 \\
\hline Object Value $(m *)$ & 0.02 & 0.0002 & 0.005 \\
\hline
\end{tabular}

${ }^{a_{S}}$ Starting values are taken from the results of the quadratic program (i.e., values of the third column in Table 2).

${ }^{b}$ Starting values are taken from the results of the eigenvalue procedure (i.e., values of the last column in Table 2).

${ }^{c}$ All starting values are given as one. 
Appendix 1

Composition of 6 Quality of Life Indices

I. Components of the Economic Index

1) Individual Economic Well-being

A. Income

1. personal income per capita

2. median income of 4-person families

(No. 751, SA, 1984)

B. Wealth

1. savings per capita

2. percent of owner-occupied housing units

3. asset per capita

(No. 751, SA, 1984)

(No. 833, SA, 1985)

(No. 1341, SA, 1984)

(No. 773, SA, 1985)

2) Community Economic Health
A. Income Distribution
1. percent of persons below poverty level
2. ratio of highest percentile to lowest

B. Employment

1. unemployment rate

2. labor force participation rate

3. female participation rate

4. wage rate

5. percent of insured unemployed

C. Degree of Economic Concentration

1. concentration rate

D. Productivity

1. value added in manufacturing

2. value added in retail

3. value added in wholesale

4. value added in services

E. Capital Availability

1. total bank deposits per capita

(No. 783, SA, 1984)

(No. 751, SA, 1984)

(No. 686, SA, 1985)

(No. 673, SA, 1984)

(No. 673, SA, 1984)

(No. 714, SA, 1984)

(No. 703, SA, 1984)

(calculated by author)

(No. 1341, SA, 1985)

(No. 1407, SA, 1985)

(No. 1416, SA, 1985)

(No. 1423, SA, 1985)

(No. 826, SA, 1985)

II. Components of the Education Index

1) Individual Condition

1. median school years completed by persons 25 years old and over

2. educational expenditure per pupil

3. average teacher's salary in public schools

4. percent of population enrolled in higher education

5. ratio of per capita education expenditure to per capita income

III. Components of the Environmental Index

1) Air pollution

1. tons of particulate emissions per year per acre

(NER, 1983)

2. tons of sulfur oxide emissions per year per acre

(NER, 1983)

3. tons of carbon monoxide emissions per year per acre

(NER, 1983)

4. tons of nitrogen oxide emissions per year per acre

(NER, 1983)

2) Noise

5. tons of volatile compounds emissions per year per acre (NER, 1983)

(Table 23, COP, 1984)

(No. 239, SA, 1984)

(No. 245, SA, 1983)

(Table 71, DES, 1984)

(Table 11, DES, 1984)

1. population density (No. 11, SA, 1984)

2. registered motor vehicles per 1000 population

(No. 1035, SA, 1985)

3. registered cycles per 1000 population

(No. 1035, SA, 1985)

3) Water

1. clean water consumption per day

(No. 1062, SA, 1984) 
IV. Components of Health Index

1) Individual Conditions

1. infant mortality rate

(No. 109, SA, 1985)

2. death rate

3. personal health care expenditure

(No. 107, SA,1985)

2) Community Conditions

1. dentists per 1000 population

2. physicians per $\mathbf{1 0 0 0}$ population

3. hospital beds per 1000 population

(No. 150, SA, 1984)

4. hospital occupancy rates

5. daily room charge

6. nursing beds per 1000 population

7. state and local government health expenditure

(No. 159, SA, 1985)

(No. 159, SA, 1985)

(No. 167, SA, 1985)

(No. 167, SA, 1985)

(No. 171, SA, 1984)

(No. 167, SA, 1985)

8. mental patients per 1000 population

(No. 167, SA, 1985)

(No. 182, SA 1984)

V. Components of the Political Index

1) Individual Participation

1. presidential election voting rate

(No. 423, SA, 1985)

2) State Local Government

A. Professionalism

1. total municipal employment per 1000 population

(No. 492, SA, 1984)

2. police and fire protection employment per 1000 population

3. public welfare employment per 1000 population

(No. 492, SA, 1984)

B. Performance

1. revenue per capita

2. percent of federal government aid in total revenue

3. debt outstanding per capita

4. tax base (approximate market value of locally assessed ordinary realty per capita)

(No. 492, SA, 1984)

(No. 454, SA, 1984)

(No. 454, SA, 1984)

(No. 454, SA, 1984)

(No. 465, SA, 1984)

C. Welfare Assistance

1. per capita welfare expenditure

2. monthly benefits of retired workers

3. monthly benefits of disabled workers

No. 454, SA, 1984)

(No. 523, SA, 1984)

(No. 523, SA, 1984)

4. monthly benefits of widows and widowers

(No. 523, SA, 1984)

VI. Components of the Social Index

1) Individual Concerns

A. Family Life

1. divorce rate

2. marriage rate

B. Information

1. newspaper circulations per 100 population

(No. 122, SA, 1985)

(Table A, CCDB, 1983)

C. Others

1. suicide rate

2. labor union rate

(No. 940, SA, 1985)

(No. 112, SA, 1985)

(No. 709, SA, 1985)

2) Community Living Condition

A. Public Safety and Law Enforcement

1. crime rates

2. number of policemen per 1000 population

3. population-lawyer ratio

(No. 277, SA, 1984)

(No. 492, SA, 1984)

(No. 301, SA, 1985)

B. Housing Condition

1. housing units with 1.01 or more persons per room

(No. 1312, SA, 1984)

2. housing units lacking complete plumbing

3. monthly owner cost of specified housing

4. median values of specified housing

(Table A, CCDB, 1984)

(No. 1312, SA 1984)

(No. 1312, SA, 1984) 
C. Leisure and Recreation

1. park areas per 1000 population

(No. 390, SA, 1984)

2. average working hours per week in manufacturing industry

(No. 714, SA, 1984)

D. Transportation Condition

1. highway mileage per car

2. public transportation utilization rate

3. state highway maintenance cost per highway mileage

Note: The sources of these data appear in parenthesis

$\begin{array}{ll}\text { Abbreviation: } & \\ \text { SA: } & \text { Statistical Abstract of United States } \\ \text { COP: } & \text { Census of Population } \\ \text { DES: } & \text { Digest of Education Statistics } \\ \text { NER: } & \text { National Emission Report } \\ \text { CCDB: } & \text { County and City Data Book }\end{array}$

APPENDIX 2

Composition of 8 Quality of Life Indexes

I. Health Index

1. long life (death rate)

2. disability (resident patients per 1000 residents in mental care hospital)

3. access to medical care (per capita health expenditure)

II. Public Safety Index

1. crime (crime rate)

2. security (number of policement per 1000 resident)

III. Education Index

1. attainment (percent of persons 25 years and over, who completed 4 years of high school or more)

2. achievement (education expenditure per pupil)

3. higher and continuing education (percent of population enrolled in higher education)

IV. Employment Index

1. employment opportunity (unemployment rate, female labor participation rate)

2. working conditions (average weekly wage rate)

V. Income Index

1. level of income (personal income per capita)

2. expenditure of income (asset per capita)

3. lower income population (poverty level)

VI. Housing Index

1. living space (percent of housing with 1.01 or more persons per room)

2. housing unit (percent of housing lacking complete plumbing facility)

VII. Leisure and Recreation Index

1. leisure time (average working hours per week)

2. outdoor recreation (park areas per 1000 residents)

VIII. Air Pollution \& Noise Index

1. air quality (sulfur oxide emissions per year per acre)

2. congestion (population density) 